Development of a clay based bioink for 3D cell printing for skeletal application

This content has been downloaded from IOPscience. Please scroll down to see the full text.

Download details:

IP Address: 152.78.77.139

This content was downloaded on 11/07/2017 at 16:07

Manuscript version: Accepted Manuscript

Ahlfeld et al

To cite this article before publication: Ahlfeld et al, 2017, Biofabrication, at press:

https://doi.org/10.1088/1758-5090/aa7e96

This Accepted Manuscript is: (c) 2017 IOP Publishing Ltd

During the embargo period (the 12 month period from the publication of the Version of Record of this article), the Accepted Manuscript is fully protected by copyright and cannot be reused or reposted elsewhere.

As the Version of Record of this article is going to be / has been published on a subscription basis, this Accepted Manuscript is available for reuse under a CC BY-NC-ND 3.0 licence after the 12 month embargo period.

After the embargo period, everyone is permitted to copy and redistribute this article for non-commercial purposes only, provided that they adhere to all the terms of the licence https://creativecommons.org/licences/by-nc-nd/3.0

Although reasonable endeavours have been taken to obtain all necessary permissions from third parties to include their copyrighted content within this article, their full citation and copyright line may not be present in this Accepted Manuscript version. Before using any content from this article, please refer to the Version of Record on IOPscience once published for full citation and copyright details, as permission will likely be required. All third party content is fully copyright protected, unless specifically stated otherwise in the figure caption in the Version of Record.

When available, you can view the Version of Record for this article at:

http://iopscience.iop.org/article/10.1088/1758-5090/aa7e96 


\title{
Development of a clay based bioink for 3D cell printing
} for skeletal application

\author{
T. Ahlfeld ${ }^{\S 1}$ \& G. Cidonio ${ }^{\S 2,3}$, D. Kilian ${ }^{1}$, S. Duin ${ }^{1}$, A. R. Akkineni ${ }^{1}$, J. I. Dawson ${ }^{2}$, S. Yang 3 ,
} A. Lode ${ }^{1}$, R.O.C. Oreffo ${ }^{2 *}$, M. Gelinsky ${ }^{1 *}$

${ }^{\S}$ These authors contributed equally

${ }^{1}$ Centre for Translational Bone, Joint and Soft Tissue Research, University Hospital Carl Gustav Carus and Faculty of Medicine, Technische Universität Dresden, Dresden, Germany

${ }^{2}$ Bone and Joint Research Group, Centre for Human Development, Stem Cells and Regeneration, Institute of Developmental Sciences, University of Southampton, Southampton, UK

${ }^{3}$ Engineering Materials Research Group, Faculty of Engineering and the Environment, University of Southampton, Southampton, UK

Email: michael.gelinsky@tu-dresden.de; richard.oreffo@soton.ac.uk Keywords: Laponite, bioink, bioprinting, growth factor delivery, hydrogels, additive manufacturing 


\begin{abstract}
Three-dimensional printing of cell-laden hydrogels has evolved as a promising approach on the route to patient-specific or complex tissue engineered constructs. However, it is still challenging to print structures with both, high shape fidelity and cell vitality. Herein, we used a synthetic nanosilicate clay, called Laponite, to build up scaffolds utilizing the extrusion-based method 3D plotting. By blending with alginate and methylcellulose, a bioink was developed which allowed easy extrusion, achieving scaffolds with high printing fidelity. Following extrusion, approximately 70-75 \% of printed immortalized human mesenchymal stem cells (hTert-MSC) survived and cell viability was maintained over 21 days within the plotted constructs. Mechanical properties of scaffolds comprised of the composite bioink decreased over time when stored under cell culture conditions. Nevertheless, shape of the plotted constructs was preserved even over longer cultivation periods. Laponite is known for its favorable drug delivery properties. Two model proteins, BSA and VEGF were loaded into the bioink. We demonstrate that the release of both growth factors significantly/changed to a more sustained profile by inclusion of Laponite in comparison to an alginate-methylcellulose blend in the absence of Laponite. In summary, addition of a synthetic clay, Laponite, improved printability, increased shape fidelity and was beneficial for controlled release of biologically active agents such as growth factors.
\end{abstract}




\section{Introduction}

As more traditional additive manufacturing methods, such as 3D powder printing or selective laser sintering, are commonly used to build up 3D structures/scaffolds with complex geometries [1-4], methods like extrusion-based 3D plotting are becoming more focussed with the potential for bioprinting, namely the layer-by-layer fabrication of scaffolds including cells or biologically active factors, with the advantage of a spatially defined arrangement of cells and/or growth factors within a scaffold [5,6]. Hydrogels are commonly used for cell encapsulation given their water-rich, biocompatible environment $[7,8]$. Based on inkjet printing technologies, the term 'bioink' has been established to describe cell-containing hydrogels and was translated to materials of higher viscosity, which are useful for extrusion based bioprinting. The highly viscous properties demonstrate the pasty character of these materials; hence the term 'paste' is used for the bioink presented within this manuscript. The characteristics of the printing pastes have to be tailored with respect to both, printing fidelity and cell compatibility [9]. This includes, amongst others, parameters such as: i) viscosity of the hydrogel, ii) the gelation process, iii) the built network structure and its influence on diffusion and mechanical strength, and furthermore the induced shear stress caused by the needle gauge $[9,10]$. Crucially, printing fidelity is strongly linked to the printing of large-scale, three dimensional constructs [9]. There are two main strategies to achieve bioprinted constructs at clinically relevant dimensions by extrusion-based 3D printing in air, i.e. without using a liquid or suspension bath as supporting medium: (i) Usage of rigid support materials like poly-e-caprolactone (PCL) that acts as a shape-defining grid offering space and structural integrity to print a soft bioink between the stiff strands $[11,12]$. Furthermore, the strand morphology can be modified from a commonly extruded homogenous strand to a core/shell strand with a stiff shell surrounding a soft core presenting the bioink [13-15]. (ii) Enhancement of the rheological properties, which can be achieved either through pre-crosslinking of the paste [16], or by a crosslinking step immediately after extrusion, e.g. photopolymerization [17]. A third strategy is the temporary increase of the viscosity of the paste by the addition of hydrogels, which do not get stabilized by a further crosslinking step afterwards [18]. Schütz et al. presented an approach in which the viscosity of a $3 \mathrm{w} / \mathrm{v} \%$ alginate solution was temporarily increased during fabrication by addition of $9 \mathrm{w} / \mathrm{v} \%$ methylcellulose to achieve a paste with high viscosity, strong shear thinning/behaviour and therefore good printing fidelity [19]. As methylcellulose is not ionically crosslinked, it was washed out and the alginate, crosslinked by calcium ions, retained the shape of the scaffolds. Extrusion-based printing (3D plotting) of the alginate/methylcellulose blend laden with human mesenchymal stromal cells (hMSC) revealed that 3D constructs with clinically relevant dimensions could be achieved and that a significant proportion of the cells survived the plotting process, however, methylcellulose did not show any functional or biological benefit for the resulting hydrogel matrix. This aspect is addressed in the present work, through the addition of Laponite, a nanosilicate clay with high potential for tissue engineering purposes, in favour of methylcellulose.

Laponite is a synthetic magnesium silicate clay widely employed as filler or thickening agent in the cosmetic industry [20]. Laponite offers significant potential for tissue engineering applications [21] and has been shown to augment cell spreading and osteogenesis in tissue engineered constructs $[22,23]$. The crystalline structure of Laponite consists of layered silicate similar to other clay minerals housing a central magnesium core between two silica sheets. Laponite comprises disc-shaped particles of about $25 \mathrm{~nm}$ in diameter and $1 \mathrm{~nm}$ in thickness. With a highly negatively charged face and a positively charged rim, Laponite particles can self-assemble through electrostatic interactions to form gel (or glassy) states showing typical characteristics of shear-thinning gels [21,24-26]. Nanosilicates have been widely employed in tissue engineering applications $[21,27]$. Blended with polymers, 
beneficial improvements of mechanical and biological properties have been found to be a direct consequence of the physical strong interaction between polymeric chains and monodispersed clay [21]. For example, a Laponite gel has been used as bioactive excipient in combination with gelatine methacrylate (GelMA) resulting in a biocompatible hydrogel that could stimulate cell adhesion, proliferation and differentiation [22]. Laponite has been applied as drug delivery agent and proved capable of localising and delivering albumin, lysozyme and bioactive vascular endothelial growth factor (VEGF) in a sustained manner [26]. Crucially, degradation products of Laponite such as $\mathrm{Na}^{+}$, $\mathrm{Mg}^{2+}, \mathrm{Si}(\mathrm{OH})_{4}$ and $\mathrm{Li}^{+}$are non-toxic and may also exhibit a positive influence on bone metabolism and calcification [28]. Moreover, Laponite continues to attract much interest as rheological enhancer of polymeric solutions, due to its strong shear-thinning properties $[29,30]$.

Alginate is widely used for cell encapsulation and 3D printing applications [31-34]. Ghadiri et al. showed that the combination of Laponite and alginate increased the viscosity of an injectable hydrogel and improved the Young's modulus of crosslinked scaffolds [35]. Recently, Laponitealginate gels have been shown to sustain the release of cationic drugs [36]. For example, the suspension significantly improved the release kinetics of Doxorubicin [37]. The suspension of Laponite and alginate has been studied for 3D printing by Hong et al. [38]. The authors reported, that printing of Laponite-alginate was not possible. Printable pastes were achieved in combination with 40 $\%$ poly(ethylene glycol) diacrylate resulting in the fabrication of scaffolds with high toughness and stretchability were fabricated [38], however, the potential of this material combination for bioprinting remains to be demonstrated. Most recently, Jin et al. reported on a highly concentrated Laponitealginate blend with enhanced shape fidelity, which was seeded with cells after printing [39]. The blend revealed enhanced printability and biocompatibility.

In the present work, we have used 3D plotting as fabrication method for a new developed bioink based on Laponite, alginate and methylcellulose. 3D plotting is an extrusion-based method, without the requirement for high temperatures enabling fabrication at room temperature or physiological conditions [40]. The integration of Laponite led to a decrease of the requisite methylcellulose, while the printing fidelity was maintained as indicated by scaffolds, which could be fabricated in clinical relevant dimensions with high shape fidelity. Moreover, cell survival was observed to be increased in comparison to alginate-methylcellulose scaffolds. In addition, we demonstrate high cell viability of hTERT-MSC after extrusion. The current studies demonstrate the new bioink displayed significant mechanical weakening in vitro, probably due to the interaction of nanosilicates and alginate. Laponite inside the alginate-methylcellulose blend led to favourable drug delivery properties evidenced by sustained release of a model protein BSA and an angiogenic relevant growth factor VEGF.

\section{Materials and methods}

\subsection{Paste preparation}

The composition of the plotting pastes tested in this study is shown in Table $1.0 .3 \mathrm{~g}$ of Laponite powder (Laponite XLG, BYK Additives \& Instruments, UK) was dispersed under rapid agitation in $10 \mathrm{ml}$ deionized water. For the blends, $0.3 \mathrm{~g}$ alginate (alginic acid sodium salt from brown algae, 71238, Sigma, UK, M/G ratio 1:2) were added and dissolved under stirring until a homogeneous solution was obtained. Optionally, 0.3 or $0.6 \mathrm{~g}$ methylcellulose powder (M0512, Sigma, USA, molecular weight $\approx 88,000 \mathrm{Da}, 4,0000 \mathrm{cP} \bullet \mathrm{s}$ ) were carefully mixed in with a spatula; the resulting blends were set over night to allow swelling of the methylcellulose. Pure methylcellulose was made accordingly by dissolving $0.3 \mathrm{~g}$ of the raw powder in $10 \mathrm{ml}$ water. Materials for cell incorporation were sterilized by autoclaving. $3 \mathrm{w} / \mathrm{v} \%$ alginate $/ 9 \mathrm{w} / \mathrm{v} \%$ methylcellulose was prepared as described by Schütz et al. [19]. Briefly, alginate was dissolved in PBS overnight. Autoclaved methylcellulose 
was subsequently added and swelling of methylcellulose was allowed for $2 \mathrm{~h}$ to obtain a plottable paste.

Table 1: Nomenclature of the tested pastes (all numbers in weight-\%)

\begin{tabular}{cccc}
\hline Label & Laponite & Alginate & Methylcellulose \\
\hline $3-0-0$ & 3 & 0 & 0 \\
$0-0-3$ & 0 & 0 & 3 \\
$3-3-0$ & 3 & 3 & 0 \\
$3-3-3$ & 3 & 3 & 3 \\
$3-3-6$ & 3 & 3 & 6 \\
$0-3-9$ & 0 & 3 & 9 \\
\hline
\end{tabular}

\subsection{Rheology}

Viscosity of the pastes was measured both at constant and increasing shear rates using a plate rheometer (Rheotest RN 4, Medingen, Germany) with a plate-plate-distance of $0.1 \mathrm{~mm}$. Viscosity of the pastes was determined by applying a constant shear rate of $10 \mathrm{~s}^{-1}$ for $300 \mathrm{~s}$. Shear thinning was tested by increasing the shear rate from $0-50 \mathrm{~s}^{-1}$ over $600 \mathrm{~s}$ (increment $=0.08 \mathrm{~s}^{-1}$ ). After an initial amplitude sweep test to detect the viscoelastic region, oscillatory frequency sweep tests ( $\mathrm{f}=0.01 \mathrm{~s}^{-1}$ $10 \mathrm{~s}^{-1}$ ) were performed on 0-0-3, 3-3-0 and 3-3-3 pastes (see table 1 for labels) and storage modulus as well as loss modulus were measured.

\subsection{Scaffold fabrication}

The 3-3-3 paste was used for scaffold fabrication and cell plotting. The paste was extruded through $\gamma-$ irradiated conical plastic needles with an inner diameter of $410 \mu \mathrm{m}$ using compressed air (air pressure: 80-95 kPa); 3D plotting was conducted in air using a Bioscaffolder 3.1 (GeSiM, Radeberg, Germany) with a speed of $8-10 \mathrm{~mm} \mathrm{~s}^{-1}$. Scaffolds were plotted in different dimensions. If not differently detailed within this manuscript, scaffolds were plotted with a base of $10 \times 10 \mathrm{~mm}^{2}$ with an alternating layer pattern $\left(\mathrm{ABAB}, 0^{\circ} / 90^{\circ}\right)$, a layer height of $230 \mu \mathrm{m}$ and a strand distance of $2 \mathrm{~mm}$. Immediately after plotting, scaffolds were incubated for $10 \mathrm{~min}$ in $100 \mathrm{mM} \mathrm{CaCl}_{2}$ solution to enable crosslinking.

\subsection{Characterization of the plotted scaffolds}

\subsubsection{Microscopy}

Macroporous structure of the scaffolds was imaged using a stereo light microscope (Leica M205 C equipped with DFC295 camera, Germany). Further analysis was performed using scanning electron microscopy (SEM; Philips XL 30/ESEM, operated in SEM mode) at a voltage of $3 \mathrm{kV}$ (spot size 3) with field emission gun. Prior to SEM, samples were dehydrated through an ascending ethanol series ending in $100 \%$ ethanol and finally by critical point drying. Energy dispersive electron spectroscopy (EDX) mapping was performed at a voltage of $12 \mathrm{kV}$.

\subsubsection{Volumetric strand swelling}

Volumetric swelling of the plotted scaffolds was investigated by measuring the strand width at different time points: before crosslinking, after crosslinking, and after 1, 2, 3, 5, 7, 14 and 21 days of incubation in cell culture medium consisting of DMEM (Dulbecco's Modified Eagle's Medium, Gibco, Thermo Fisher), $10 \%$ fetal calf serum (FCS), $100 \mathrm{U} / \mathrm{ml}$ penicillin and $100 \mathrm{mg} / \mathrm{ml}$ streptomycin (Pen/Strep) (all from Biochrom, Berlin, Germany) under cell culture conditions. For measuring, pictures of different scaffolds $(\mathrm{n}=5)$ were taken by stereo light microscopy and analysed with ImageJ (1.44p, National Institutes of Health, Bethesda, Maryland, USA). 


\subsubsection{Mechanical test}

To evaluate the mechanical behaviour of the plotted scaffolds, two different geometries were compared: a porous scaffold with a strand distance of $2 \mathrm{~mm}$ and a solid scaffold without pores obtained by depositing strands next to each other without a strand gap. Uniaxial compressive tests were applied to scaffolds $\left(1=10 \times 10 \mathrm{~mm}^{2}, \mathrm{~h}=5 \mathrm{~mm}\right)$ after 1 day and 21 days of incubation in cell culture medium and Young's modulus and compressive strength were obtained from the data. Furthermore, dynamic mechanical analysis (DMA) was performed to investigate the resistance of the scaffolds against shear stress. Therefore, frequency sweep tests $\left(f=0.01 \mathrm{~s}^{-1}-10 \mathrm{~s}^{-1}\right)$ were applied with a plate rheometer (Rheotest RN 4). Scaffolds were twisted between two plates at a strain of $10 \%$ and the storage moduli were measured.

\subsection{Fabrication of cell-laden scaffolds}

For cell plotting, an immortalized human mesenchymal stem cell line expressing hTERT (human telomerase reverse transcriptase) [41] was used. The hTERT-MSC were kindly provided by Prof. Matthias Schieker (Laboratory of Experimental Surgery and Regenerative Medicine, University Hospital Munich (LMU), Germany). The cells were expanded in cell culture medium (DMEM $+10 \%$ FCS + Pen/Strep); after harvesting, $5 \times 10^{6}$ cells were suspended in $100 \mu 1$ of cell culture medium and then carefully mixed into $1 \mathrm{~g}$ of the 3-3-3 blend. 3D plotting of cell-laden scaffolds was performed with the parameters mentioned before, crosslinking was carried out following incubation in $100 \mathrm{mM}$ $\mathrm{CaCl}_{2}$ for $10 \mathrm{~min}$.

\subsubsection{Viability of cells in plotted scaffolds}

Initially, hTERT-MSC were labelled using lipophilic carbocyanine DiD (1,1'-dioctadecyl-3,3,3',3'tetramethylindodicarbocyanine) (Vybrant DiD cell-labelling solution, Thermo Fisher Scientific) following the manufacturer's protocol. Living cells were identified by Calcein AM staining (Molecular Probes, Eugene, OR, USA) after 1, 7, 14 and 21 days. Viable cells were marked with both, DiD and Calcein staining while dead cells only showed DiD signal. Therefore, conclusions on cell viability ratio could be drawn following confocal laser scanning microscopy (cLSM) (Leica TCS SP5, Leica Microsystems, Wetzlar, Germany) at specific fluorescence wave lengths of DiD (Ex: $644 \mathrm{~nm}$; Em: $665 \mathrm{~nm}$ ) and Calcein (Ex: $494 \mathrm{~nm}$; Em: $517 \mathrm{~nm}$ ). Quantification of the percentage of living cells was achieved by relating the number of Calcein stained cells (green) to the number of DiD stained cells (red). Therefore, three scaffolds per time point were imaged at five positions, respectively. The resulting z-stacks were analysed. Counting was performed by the particle analyser of ImageJ (1.44p, National Institutes of Health, Bethesda, Maryland, USA). To avoid artefacts of fluorescent Laponite, cell sizes were evaluated to be in dimensions of 20-600 pixel.

\subsubsection{Cell density determination}

Cell density within the scaffolds at different time points was calculated by evaluation of the confocal pictures, utilizing ImageJ Particle analyser. Areas of $800 \mathrm{x} 800 \mu \mathrm{m}^{2}$ were analysed with respect to the stack height. Resulting cell numbers were divided by the observed scaffold volume.

\subsection{Protein and growth factor release \\ 2.6.1. BSA loading and release}

Bovine serum albumin (BSA, Sigma-Aldrich) was loaded within the 3-3-3 paste by adding $100 \mu \mathrm{l}$ of BSA stock solution $\left(\mathrm{c}=10 \mathrm{mg} \mathrm{ml}^{-1}\right)$ to $1 \mathrm{~g}$ of the paste. To examine the influence of Laponite, release was compared to a Laponite-free paste, 0-3-9, which was loaded equally. Immediately after loading, the pastes were applied for plotting scaffolds (4 layers, $10 \times 10 \mathrm{~mm}^{2}$ ), followed by crosslinking with a $100 \mathrm{mM} \mathrm{CaCl}_{2}$ solution for $10 \mathrm{~min}$. Samples $(\mathrm{n}=5)$ were incubated in $1 \mathrm{ml}$ of Hank's Balanced Salt 
Solution (HBSS) at $37{ }^{\circ} \mathrm{C}$ over 21 days. Release solution was replaced after certain time points $(2 \mathrm{~h}, 4$ h, $1 \mathrm{~d}, 2 \mathrm{~d}, 3 \mathrm{~d}, 5 \mathrm{~d}, 7 \mathrm{~d}, 10 \mathrm{~d}, 14 \mathrm{~d}, 21 \mathrm{~d})$ and BSA amount in the supernatants was quantified by Bradford assay using Roti ${ }^{\circledR}$ Nanoquant (Roth, Karlsruhe, Germany).

\subsubsection{VEGF loading and release}

3-3-3 and 0-3-9 pastes were loaded with VEGF (rhVEGF-A165; Biomol, Hamburg, Germany) by mixing $100 \mu \mathrm{l}$ of VEGF stock solution $\left(\mathrm{c}=100 \mu \mathrm{g} \mathrm{ml}^{-1}\right)$ to $1 \mathrm{~g}$ of the paste. Immediately after mixing, the VEGF-containing hydrogel pastes were plotted to scaffolds (6 layers, 10x10 $\mathrm{mm}^{2}$ ), aiming a theoretical loading of $700 \mathrm{ng}$ each. After crosslinking with $100 \mathrm{mM} \mathrm{CaCl}_{2}$, samples $(\mathrm{n}=8)$ were incubated in $1 \mathrm{ml}$ of release medium consisting of Endothelial Cell Basal Medium MV (Promocell, Heidelberg, Germany) supplemented with 15\% heat-inactivated FCS and Pen/Strep under cell culture conditions. Supernatants were taken at various time points $(2 \mathrm{~h}, 4 \mathrm{~h}, 1 \mathrm{~d}, 2 \mathrm{~d}, 3 \mathrm{~d}, 5 \mathrm{~d}, 7 \mathrm{~d})$ and replaced by fresh medium. Plotted scaffolds without VEGF were used as negative controls. VEGF in the supernatants was quantified by ELISA; an endothelial cell proliferation assay was performed to study maintenance of its biological activity.

\subsubsection{ELISA for VEGF quantification}

ELISA using goat anti-human VEGF (Sigma-Aldrich) as capture and biotinylated goat anti-human VEGF (R\&D Systems, Minneapolis, USA) as detection antibody was applied as described previously [42]. VEGF standard was used to perform a calibration line.

\subsubsection{Endothelial cell proliferation assay}

Biological activity of released VEGF was previously examined as described [42]. Briefly, human dermal microvascular endothelial cells (HDMEC, Promocell) were seeded in 96 well plates (2000 cells/well) and incubated in fresh release medium (Endothelial Cell Basal Medium MV with 15\% heat-inactivated FCS and Pen/Strep), mixed 1:1 with the release solutions from either VEGF-laden samples or negative controls. After $72 \mathrm{~h}$, the cell number was determined by DNA quantification utilizing the Quantifluor ${ }^{\circledR}$ dsDNA system (Promega). Determined DNA values of VEGF-laden samples were compared to DNA of the negative-controls at every timepoint (set as 1).

\subsection{Statistical analysis}

All values were evaluated by one-way Analysis of Variance (ANOVA) followed by Bonferroni's multiple comparison tests (GraphPad Prism 7). Significant differences were assumed at $p<0.05$.

\section{Results}

\subsection{Blend preparation and evaluation of rheological behaviour}

The Laponite-alginate-methylcellulose pastes were prepared by blending $3 \mathrm{w} / \mathrm{v} \%$ of Laponite suspension with $3 \mathrm{w} / \mathrm{v} \%$ of alginate and $3 \mathrm{w} / \mathrm{v} \%$ and $6 \mathrm{w} / \mathrm{v} \%$ of methylcellulose, respectively. Viscosities of the different paste compositions are shown in figure $1 \mathrm{a}$, compared to a Laponite-free control 0-3-9. Autoclaving was chosen as the sterilization method and performed on the final paste ('autoclaving of paste') or on the powders prior to dissolving ('autoclaving of powder'). Viscosities were investigated and compared to non-autoclaved materials ('w/o autoclaving'). All groups showed that viscosity is not strongly altered following autoclaving of the final paste. In contrast, autoclaving of the powders before suspension led to significantly lower viscosities. Pure Laponite paste (3-0-0) demonstrated a low viscosity of 2-7 Pa•s. The addition of alginate (3-3-0) increased the viscosity to 7$18 \mathrm{~Pa} \cdot \mathrm{s}$. In combination with methylcellulose a paste with high viscosity increase was observed. After 
$3 \%$ methylcellulose addition (3-3-3), viscosity increased significantly to 60-100 Pa•s. Further increase of methylcellulose content (3-3-6) led to higher viscosity of 200-250 Pa・s. 0-3-9 revealed a viscosity of $42.1 \pm 5.2 \mathrm{~Pa} \cdot \mathrm{s}$, which was lower than the viscosities of the 3-3-3 pastes. All compositions showed shear thinning effects at increasing shear rates, enabling extrusion through nozzles, evidenced by pastes w/o autoclaving in figure $1 \mathrm{~b}$. Subsequently, the pastes were tested for their plotting behaviour. While pastes comprising 3-0-0 and 3-3-0 were not useful to generate three-dimensional structures (plotted strands collapsed immediately after extrusion), 3-3-3 paste allowed plotting with high shape fidelity. 3-3-3, sterilized by powder autoclaving, was extrudable at lower pressures compared to 3-3-3, which was autoclaved as paste. As expected, the 3-3-6 blend was also able to generate scaffolds with excellent shape fidelity, although needed high pneumatic air pressures $(>250$ $\mathrm{kPa}$ ) for extrusion, which may have been to harmful for cell plotting. Therefore, a 3-3-3 blend, powder autoclaved, was chosen as a suitable paste for bioprinting, given the excellent shape fidelity of the plotted constructs, as well as the modest pressure $(80 \mathrm{kPa})$ needed for extrusion. All further results relate to scaffolds, fabricated using this material. Figure $1 \mathrm{c}$ shows oscillatory frequency sweep tests of the powder autoclaved 3-3-3 blend in comparison to pure methylcellulose (0-0-3) and the blend without methylcellulose (3-3-0). The pastes revealed viscoelastic behaviour and had been tested at an amplitude of the viscoelastic region, determined by amplitude sweep tests (data not shown). The storage modulus G' can be seen as an elastic, gelled component, while the loss modulus G', describes the viscous, non-gelled component of the paste. The 3-3-0 and 3-3-3 pastes displayed a higher storage modulus than loss modulus over a broad range of angular velocities. 0-0-3 had a higher loss modulus until an angular velocity of $24.5 \mathrm{~s}^{-1}$. At this crossover point, the paste lost its viscous properties and behaved like an elastic solid, evidenced by the higher shear modulus.

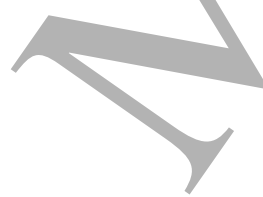


a

b

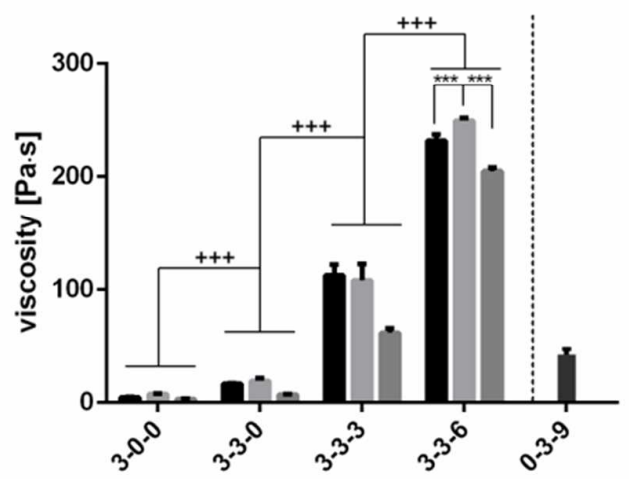

w/o autoclaving autoclaving of paste autoclaving of powder

Figure 1: Rheological properties of different pastes consisting of Laponite, alginate and methylcellulose at room temperature. (a) Viscosity at a constant shear rate of $10 \mathrm{~s}^{-1}$. The low viscosity of Laponite (3-0-0) was increased by addition of alginate (3-3-0) and further strongly increased by blending with methylcellulose (3-3-3, 3-3-6). Autoclaving of the paste did not affect the viscosity. The viscosity of a plottable 0-3-9 paste was lower than the viscosities of the 3-3-3 pastes. (b) Shear thinning of not autoclaved pastes at increasing shear rates. (c) Frequency sweep measurements of different pastes (autoclaved powders). 3-3-3 and 3-3-0 showed a storage modulus ( $G^{\prime}$ ) higher than the loss modulus (G'). For pure methylcellulose (0-0-3), a higher loss modulus was observed at lower angular speeds. (mean $\pm \mathrm{SD}, * * * \mathrm{p}<0.001,+++\mathrm{p}<0.001, \mathrm{n}=3$ )

\subsection{3-3-3 plotted scaffolds with high shape fidelity and appearance of plotted structures}

Plotting of the 3-3-3 paste was successfully performed without any stabilizing liquid by extrusion in air using a dosing needle with an inner diameter of $410 \mu \mathrm{m}$. After crosslinking, constructs of high 
accuracy in dimensions suitable for cell culture and clinical applications $\left(20 \times 20 \mathrm{~mm}^{2}\right)$ were achieved (figure 2). Tubular, vessel-like structures (figure $2 \mathrm{a}, \mathrm{b}$ ) were plotted without limitations at scaffold heights of $2 \mathrm{~cm}$. Cubic structures with 30 layers revealed shape preservation with increasing height (figure $2 \mathrm{c}, \mathrm{d})$. Figure $2 \mathrm{e}$-h show complex geometries plotted by change of the layer orientations $\left(20^{\circ}\right.$, $\left.45^{\circ}, 60^{\circ}, 72^{\circ}\right)$, remained stable after crosslinking yielding different pore geometries. By changing the stacking sequence from $\mathrm{ABAB}\left(0^{\circ} / 90^{\circ} / 0^{\circ} / 90^{\circ}\right)$ to $\mathrm{AABB}\left(0^{\circ} / 0^{\circ} / 90^{\circ} / 90^{\circ}\right)$, pores in lateral direction were formed and stayed stable even at profiles with more than 25 layers (figure $2 \mathrm{i}, \mathrm{j}$ ).

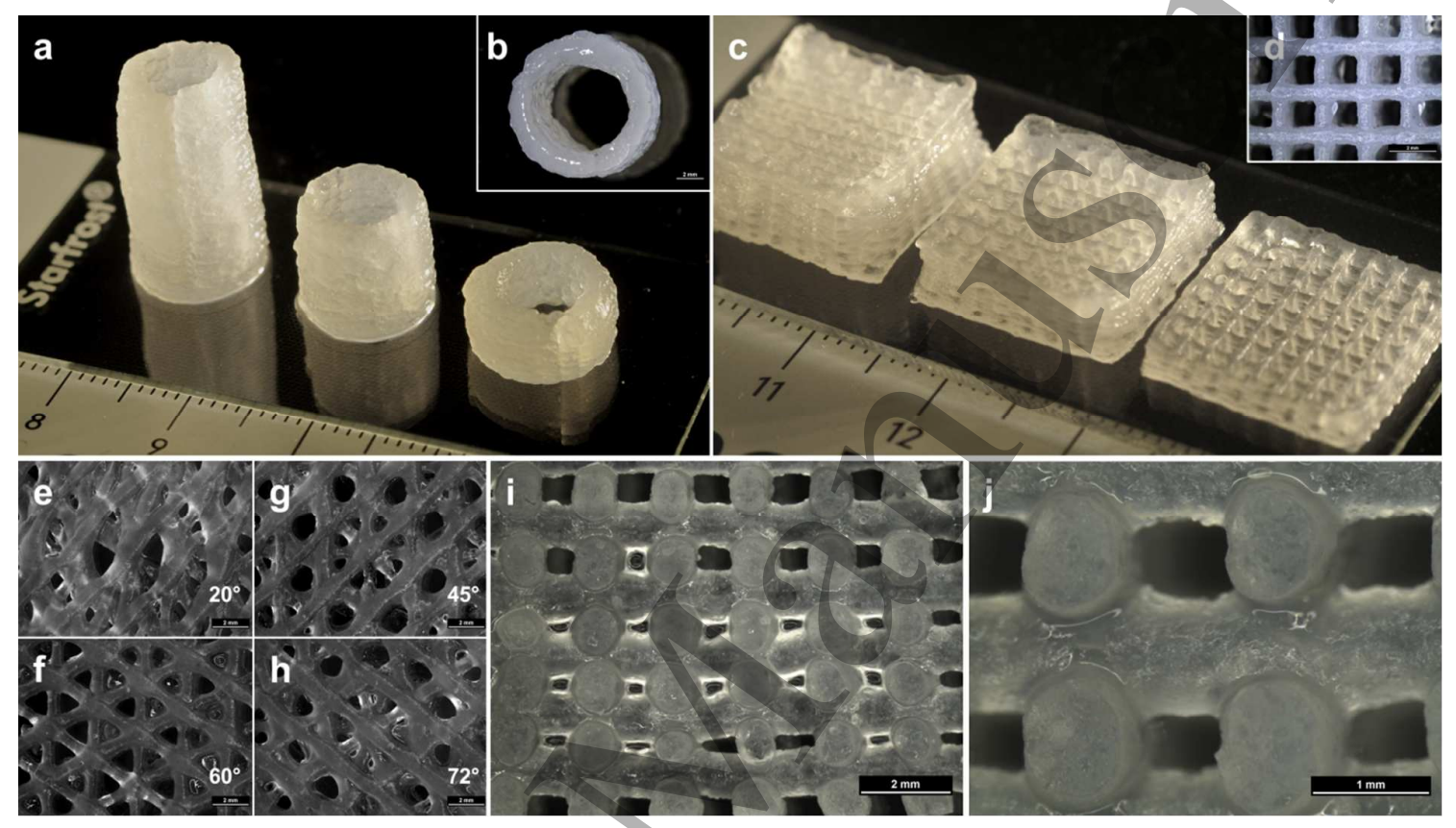

Figure 2: Scaffolds can be plotted from the 3-3-3 paste with high accuracy in clinically relevant dimensions and shapes. (a) Tube-like structures with varying heights $(2 \mathrm{~cm}, 1.5 \mathrm{~cm}, 1 \mathrm{~cm})$. (b) Top view of tube $(2 \mathrm{~cm})$. (c) Cubic structures with 30, 20 and 10 layers. (d) Top view of cube (30 layers). (e-h) Top view of scaffolds with different layer orientations (i,j) Pores in lateral direction in scaffolds with double layers (AABB).

SEM analysis of 3-3-3 plotted scaffolds revealed differences of the microstructure between the outer surface and the inner structure of the strands. Figure 3 shows a top view of the observed surfaces $(\mathrm{a}, \mathrm{b}, \mathrm{e}, \mathrm{f})$ with a dense, smooth surface, which remained predominantly unaltered over 21 days of culture. The lateral view of sliced scaffolds (c,d,g,h) displayed inhomogeneous strand structures with rough (i,iii) and smooth (ii,iv) areas. The rough surfaces appeared porous and netlike, while the smooth surfaces were noted to be dense and compact. After 21 days, these surfaces appeared smoother in contrast to day 1.

Energy-dispersive X-ray spectroscopy (EDX) analysis demonstrated the presence of Laponite and integration within the plotted structure (figure 4). As expected, a small amount of sodium was detected, arising from alginate and Laponite crystal structure. Moreover, calcium ions were observed, as a consequence of crosslinking with the $\mathrm{CaCl}_{2}$ solution. Mapping of silicon and magnesium, shown in figure $4 \mathrm{c}-\mathrm{f}$, revealed distribution of Laponite across the whole cross-section of the strand. However, silicon and magnesium were noted to be heterogeneously distributed evidenced by areas in which these ions could not be detected. 

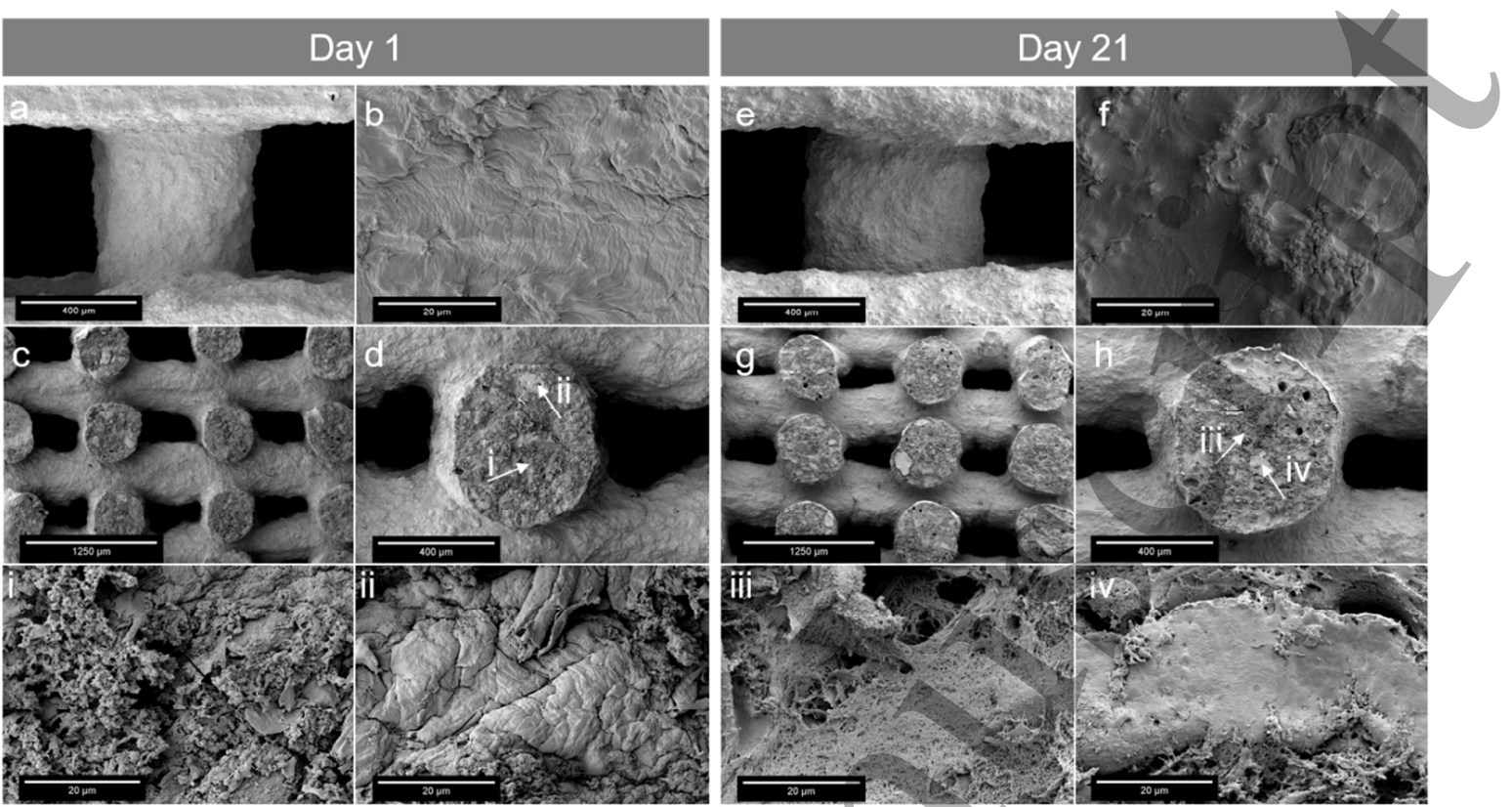

Figure 3: SEM pictures of plotted 3-3-3 scaffolds after 1 day and 21 days of incubation under cell culture conditions. The top view (a,b,e,f) revealed strands with low roughness. Side views of cut, double-layered scaffolds (stacking sequence: AABB) (c,d,g,h) showed lateral macropores and a more heterogeneous appearance of the strand cross sections with different areas, marked by white arrows and shown at higher magnification (i,ii,iii,iv).


Figure 4: EDX and EDX mapping of a cross section of a plotted 3-3-3 strand. (a,b) EDX element analysis revealed characteristic peaks of Laponite. (c-f) Element mapping of Si and $\mathrm{Mg}$ and its merge showed heterogeneous distribution of Laponite over the whole cross-section. 


\subsection{In vitro stability of plotted 3-3-3 scaffolds}

Plotted 3-3-3 scaffolds were crosslinked using $100 \mathrm{mM} \mathrm{CaCl}_{2}$ solution and incubated in cell culture medium over 21 days. At fixed time points, the scaffolds were imaged and strand diameters were determined (Figure 5). After plotting, the strand diameter was noted to be $420 \pm 32 \mu \mathrm{m}$, which is slightly larger than the needle diameter $(410 \mu \mathrm{m})$. After $10 \mathrm{~min}$ incubation in $\mathrm{CaCl}_{2}$ solution, the strand diameter increased significantly to $500 \pm 57 \mu \mathrm{m}$. Following incubation in cell culture medium, the strands were observed to further swell slightly to a diameter of $553 \pm 49 \mu \mathrm{m}$ within the first $6 \mathrm{~h}$. After day 7, no significant changes in the strand diameter were detected. After 14 days, strand diameter increased to $607 \pm 46 \mu \mathrm{m}$, but did not change significantly until day 21 . In conclusion, the strands of plotted 3-3-3 scaffolds were observed to swell by approximately $46 \%$ after plotting and $20 \%$ after crosslinking and subsequent incubation in cell culture medium at physiological conditions $\left(37^{\circ} \mathrm{C}\right)$ over 21 days.



Figure 5: Increase of the strand diameter over time. Crucial step of swelling was the crosslinking, afterwards the strands of the scaffolds did not swell significantly in cell culture medium. After 14 days, the strand diameter increased slightly, however the scaffolds maintained their defined shape and pores (mean $\pm \mathrm{SD}, * * \mathrm{p}<0.01, * * * \mathrm{p}<0.001, \mathrm{n}=20$ ).

During incubation, it was observed that plotted scaffolds retained their three-dimensional shape. However, the scaffold handling changed dramatically, from a flexible and tough scaffold to a softer scaffold, with reduced mechanical properties. Mechanical characterization of 3-3-3 plotted scaffolds was performed to study softening over time and long-term stability of the scaffold. Young's modulus and compressive strength of uniaxial compressive tests were obtained at day 1 and 21 (figure 6 a,b). 
As expected, both the Young's modulus and the compressive strength were higher for non-porous, solid scaffolds compared to porous ones. The Young's moduli decreased significantly from day 1 to day $21(176 \pm 8.9 \mathrm{kPa}$ to $28.6 \pm 9.3 \mathrm{kPa}$ (porous) and $226 \pm 28.8 \mathrm{kPa}$ to $54 \pm 32.3 \mathrm{kPa}$ (solid), respectively). The compressive strength was also observed to change significantly from $40.8 \pm 4.7 \mathrm{kPa}$ to $1.6 \pm 0.4 \mathrm{kPa}$ (porous) and $53.8 \pm 11.4 \mathrm{kPa}$ to $8.4 \pm 3.0 \mathrm{kPa}$ (solid). Dynamic mechanical analysis (DMA) was performed on the scaffolds. After defining the viscoelastic region by amplitude sweeps (data not shown), oscillatory frequency sweeps were measured. Data obtained at day 1 demonstrated a higher storage modulus for porous scaffolds ( $730 \mathrm{~Pa})$ compared to solid scaffolds ( $\sim 70 \mathrm{~Pa}$ ) (figure 6 c). Both curves were almost constant over the observed range of angular velocities. After 21 days, both the porous and solid scaffolds exhibited increasing storage moduli with linear slopes. The storage moduli of solid scaffolds were noted to be slightly higher than those of porous scaffolds.



Figure 6: Mechanical evaluation of plotted scaffolds with pores ('porous') and without pores ('solid'): Young's modulus (a) and compressive strength (b) of both scaffold types decreased significantly from day 1 to day 21 , incubated under cell culture conditions (mean $\pm \mathrm{SD}, \mathrm{n}=5, \dagger \mathrm{p}<0.05$, $* * p<0.01, * * * p<0.001)$. Oscillatory frequency sweeps (c) revealed a strong change of the crosslinking of the scaffolds during cultivation $(n=3)$.

\subsection{Cell-laden constructs preserved morphological properties and cell viability after 21 days}

An immortalized human stem cell line (hTERT-MSC) was used to demonstrate the viability of cells encapsulated in 3D plotted constructs comprising of 4 layers (figure 7). The technique of Calcein/ethidum homodimer-1 (live/dead staining) for cell characterisation could not be used as the 
Laponite absorbed the ethidium homodimer-1 providing a misleading result. Therefore, DiD prestaining was employed to alleviate artefacts from Laponite adsorption and to show cell presence and viability (DiD signal is independent from cell viability) (figure 7: red). Crucially, we were able to demonstrate the presence of metabolically active, viable cells using Calcein (figure 7: green). The cells were observed to be distributed homogeneously over the whole scaffold retaining a round, circular morphology and an absence of cell spreading. For cell viability determination, 3-3-3 was compared to a Laponite-free 0-3-9 blend, which was developed before [19]. Comparison of the number of living cells inside the 3-3-3 blend revealed a cell viability of approximately $70-75 \%$ after plotting (figure 8 a). In the Laponite-free control, cell viability was slightly lower after plotting and significantly lower after $7 \mathrm{~d}$ (60-65\%) compared to the 3-3-3 blend. At later timepoints, cell viability within the 0-3-9 blend increased and was significantly higher after 21 days. The cell density of the plotted cell-containing scaffolds of 3-3-3 and 0-3-9 is shown in figure 8 b (day 1 set as $100 \%$ ). While the cell density inside 3-3-3 did not change significantly over time, it decreased significantly from day 1 to day 14 for the Laponite-free control $0-3-9(\mathrm{p}<0.001)$. This indicates, that the number of both, living and total cells was stable inside 3-3-3, while it decreased inside 0-3-9.

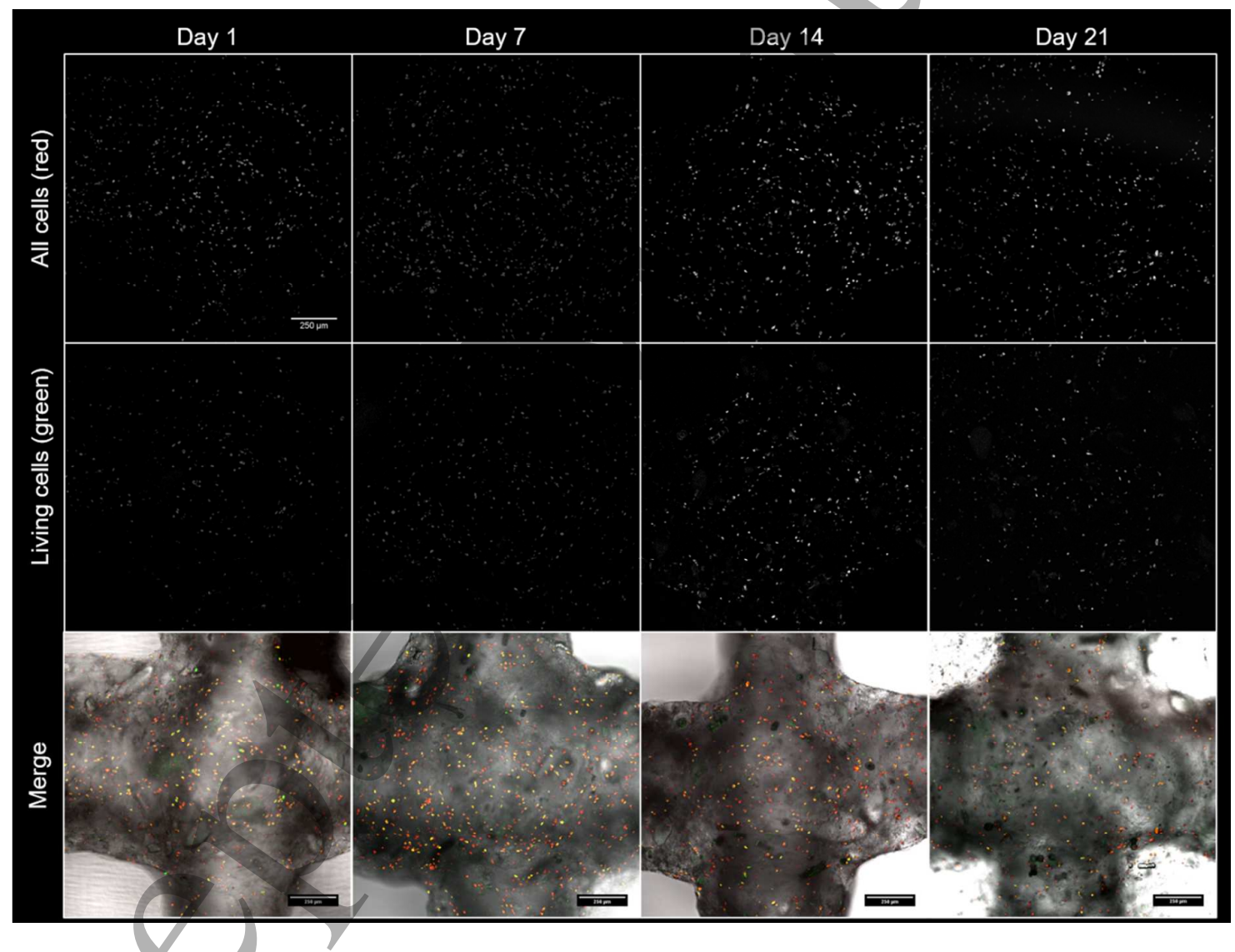

Figure 7: Confocal laser scanning microscopy (cLSM) images of all cells (red), living cells (green) and merged channels including the brightfield image as comparison over 21 days. All cells (red) were prelabelled prior to plotting with DiD lipophilic dye and represent both viable and dead cells. Metabolically active cells (green) were stained additionally with Calcein and represent the amount of living cells (scale bars $=250 \mu \mathrm{m})$. 
a



b

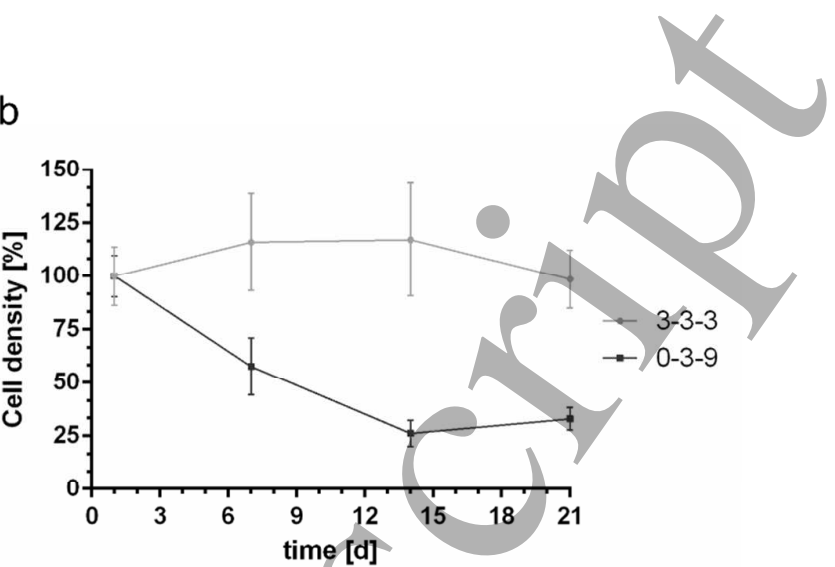

Figure 8: Ratio of viable cells in relation to total cell count over 21 days, determined by cell number analysis in cLSM pictures. (a) 3-3-3 samples revealed a cell viability of 70-75\% for all time points. The 0-3-9 control showed a lower cell viability of 60-65\% at day 1 and 7 before a higher cell viability after $14 \mathrm{~d}$ and $21 \mathrm{~d}$ was observed. (b) Cell density obtained by the image stacks (day 1 was set as $100 \%$ ). No significant change of the cell number and density was detected over a culture period of 21 days for 3-3-3 samples. The cell density of 0-3-9 decreased significantly over time. (mean $\pm \mathrm{SD}$, $\mathrm{n}=15, * * * \mathrm{p}<0.001)$

\subsection{Laponite enhanced the BSA and VEGF release kinetics of alginate-methylcellulose blends}

To study the growth factor release capabilities of plotted 3-3-3 scaffolds, the model proteins BSA and VEGF were used. To evaluate the influence of Laponite, release from a 0-3-9 blend was studied in comparison to 3-3-3 scaffolds. 3-3-3 and 0-3-9 pastes were loaded with the same amount of BSA ( $c=$ $\left.10 \mathrm{mg} \mathrm{ml}^{-1}\right)$ or VEGF $\left(\mathrm{c}=100 \mu \mathrm{g} \mathrm{ml}^{-1}\right)$ prior to plotting. Cumulative release of BSA over 21 days is shown in figure $9 \mathrm{a}$ and $\mathrm{b}$. While 0-3-9 showed a high initial burst release of 53.8 $\pm 5.7 \mu \mathrm{g}$ after $4 \mathrm{~h}$, BSA released from 3-3-3 scaffolds was observed at only $2.2 \pm 0.7 \mu \mathrm{g}$. Up to day 21 , only restricted release of BSA from 0-3-9 was measured, the cumulative release increased to a level of $61.7 \pm 6.5 \mu \mathrm{g}$. In contrast, release between $4 \mathrm{~h}$ and 21 days from 3-3-3 was significant higher and after 21 days, $18.0 \pm 1.5 \mu \mathrm{g}$ had been released. However, results indicated, that a significant amount of BSA was retained within the 3-3-3 blend. Figure $9 \mathrm{c}$ and d show the release of VEGF over 7 days. Again, 0-3-9 revealed an initial burst release, with 149.0 $\pm 12.9 \mathrm{ng}$ VEGF after $4 \mathrm{~h}$. In contrast, VEGF release from 3-3-3 scaffolds was $0.26 \pm 0.05 \mathrm{ng}$. While the release of 0-3-9 decreased with time, the cumulative release profile of 3-3-3 was almost linear, indicating a sustained release of VEGF. After 7 days, 0-3-9 showed a total release of $275.7 \pm 22.4 \mathrm{ng}$; while the 3-3-3 scaffolds released significantly less $(8.3 \pm 1.0$ ng). As observed for BSA, a significant amount of the growth factor was retained inside the 3-3-3 blend. Released VEGF from 3-3-3 maintained its bioactivity at all evaluated time points (figure 9 e). Endothelial cells, incubated in the release medium from VEGF-laden scaffolds showed enhanced proliferation in comparison to cells incubated in the supernatants of negative controls (set as 1). 
a

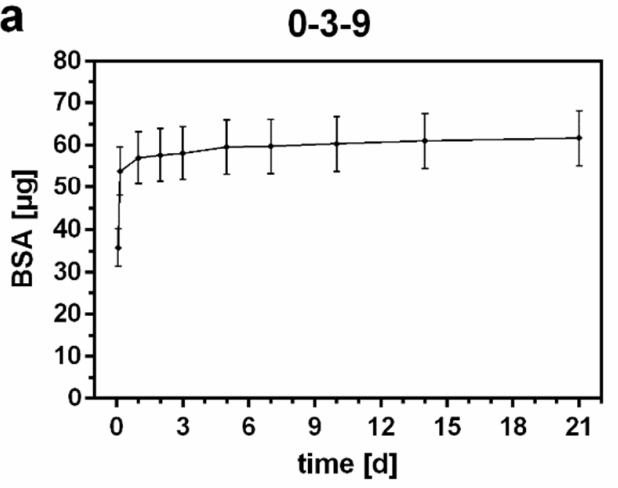

C

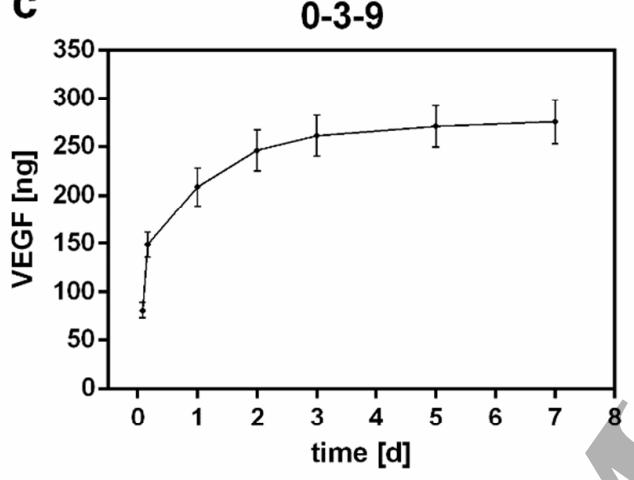

3-3-3

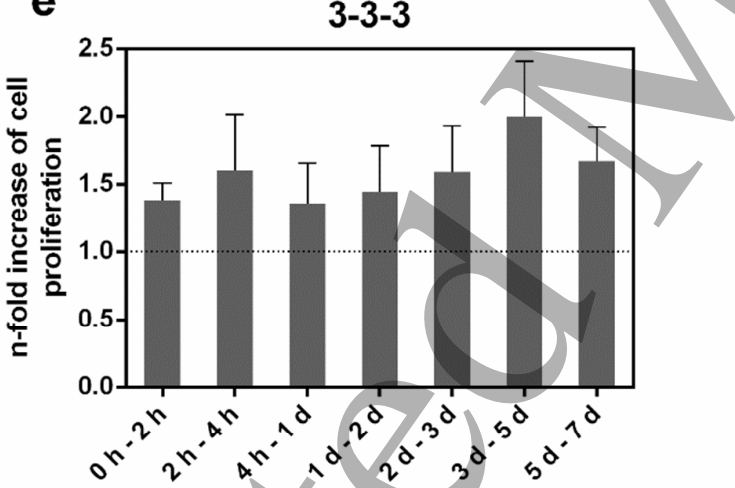

b



d

3-3-3

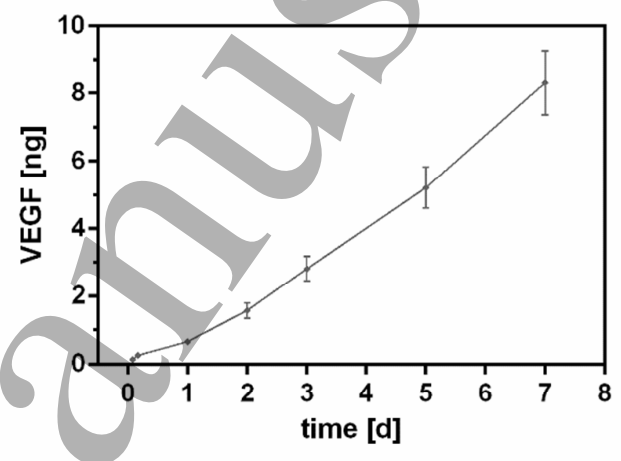

Figure 9: Release of model proteins from 0-3-9 and 3-3-3 plotted scaffolds. (a,b) Cumulative release curves of BSA. 0-3-9 showed a high initial burst, while 3-3-3 demonstrated a more sustained release. Data suggest, that a significant amount of BSA was remained inside 3-3-3 blend after 21 days. (c,d) Cumulative release curves of VEGF. Again, high initial burst was observed from 0-3-9 scaffolds, while VEGF from 3-3-3 was released in a sustained manner. After 7 days, 3-3-3 released significantly less VEGF than 0-3-9. However, from day 5 and day 7, absolute release of both scaffolds was roughly the same. (e) Bioactivity of VEGF in supernatants of 3-3-3 scaffolds in comparison to supernatants of negative controls (set as 1 ). VEGF retained its bioactivity at every time point.

\section{Discussion}

Bioprinting has evolved as excellent approach to arrange cells in an ordered fashion [43]. However, printing of three-dimensional structures with high shape fidelity while simultaneously providing an appropriate environment for embedded cells remains challenging. The approach presented in this 
paper sought to blend alginate as a bioink with two materials, methylcellulose and Laponite, in order to enhance both, viscosity and biofunctionality. Alginate was shown before to be beneficial for 3D printing applications, due to its printability and biocompatible crosslinking capabilities with calcium ions $[16,44,45]$. Earlier studies presented methylcellulose to heavily increase the viscosity of a cellladen alginate hydrogel enabling printing of scaffolds with embedded hMSC in clinically relevant dimensions [19]. Aqueous Laponite suspensions possesses shear-thinning properties drawing interest as injectable material and for 3D printing [23]. Moreover, the significant high potential of Laponite gels for cell embedding and drug delivery in tissue engineering has been demonstrated $[21,26]$.

Plain Laponite suspension only (3-0-0) as well as a Laponite-alginate combination (3-3-0) did not enable the generation of three-dimensional structures. In contrast, the addition of $3 \%$ and $6 \%$ methylcellulose (3-3-3 and 3-3-6) resulted in a significant increase in viscosity and allowed the plotting of strands with a shape fidelity comparable to the 0-3-9 blend described previously [19]. Preparation of an alginate-free paste was not possible, given methylcellulose separated from the Laponite suspension. The gel-like Laponite-alginate composite prevented phase separation of dehydrated methylcellulose agglomerates, which enabled homogeneous hydration of the methylcellulose chains resulting in a uniform paste. The reduced content of methylcellulose required to achieve appropriate plotting results is likely to have arisen from additional electrostatic interactions between Laponite surfaces and alginate chains, as demonstrated by other groups exploring Laponitealginate based nanocomposites $[35,46]$. These crosslinks were indicated by frequency sweep tests, as the shear modulus (elastic response of a hydrogel) of 3-3-0 and 3-3-3 was higher than the loss modulus (presenting the viscous response). The elastic response is mainly a consequence of crosslinks between polymer chains [10]. Earlier, the elastic response of a Laponite-polymer blend was shown to result from Laponite mediated crosslinks between the polymer chains [30]. The loss modulus of the 33-0 paste was furthermore noted to decrease over angular velocity confirming the nature of noncovalent interaction between Laponite and alginate chains. At low angular speeds, pure methylcellulose (0-0-3) had a higher loss modulus than storage modulus, demonstrating absent crosslinked polymer chains and flowing of the material. With increasing angular speeds, the chains entanglements acted increasingly like fixed junctions, resulting in a faster increasing storage modulus. Hence, after the crossover-point, when the storage modulus was higher than the loss modulus, the methylcellulose paste behaved like an elastic solid [47]. However, Laponite-alginate nanocomposite interaction remains to be fully investigated and understood. Ghadiri et al. have shown hydrogen bonds between silica nanoparticles and alginate carboxylic groups [35]. Although an interaction of methylcellulose with Laponite gel cannot be excluded, it is expected that Laponite will bind preferentially to alginate, due to the strong electrostatic polarities of Laponite and alginate and the negligible polarity of methylcellulose. Critically, Laponite-alginate composite structure assembly has not been postulated theoretically before. Thus, we hypothesize a specific supramolecular assembly interaction between Laponite and alginate. Laponite nanodiscs, given their dual ionic character, interact with guluronic and mannuronic acid groups present in the alginate polysaccharide chain occupying ionic pocket where calcium ions should be positioned, providing a temporary linkage between the long alginate molecules.

The rheological behaviour of the pastes was strongly dependent on the sterilization process. When the individual components are autoclaved, there is literature evidence for the following: (i) Alginate suspension degrades with a measurable loss of molecular weight leading to decreased viscosities [48], (ii) high temperature is likely to facilitate the Laponite gel aging process, enhancing the gel structure [49], and (iii) methylcellulose is a thermoreversible gel; at higher temperatures aggregation will occur and gelation of methylcellulose starts, resulting in higher viscosities [50]. However, after cooling 
down, gelation declines and viscosity enhancement may be caused by hydration of the polar groups of methylcellulose [51], independently of the sterilization method. In pastes, autoclaved after mixing the components, alginate degradation after sterilization was compensated by Laponite strengthened network (3-3-0). This could explain why slightly increased viscosities were measured. When autoclaving all three materials prior to mixing ('autoclaving of powders'), a strong network formation of Laponite nanodiscs did not take place. The reduction of the viscosity compared to other autoclaving methods might only be caused by alginate degradation.

Scaffolds plotted from 3-3-3 paste displayed high shape fidelity and could be plotted in clinically relevant dimensions. Importantly, through changing the stacking sequence to double layers (AABB) lateral pores were achieved. The high shape fidelity is connected to the viscosity enhancement by methylcellulose addition, which is not crosslinked by cations and therefore could diffuse out of the material blend [19]. EDX confirmed Laponite integration into the hydrogel matrix and distribution within the strands. Based on the heterogeneous pattern observed for silicon and magnesium ion distribution, it is assumed that there are areas enriched with Laponite gel adjacent to areas predominantly formed by the alginate hydrogel. Due to the differences in the chemical composition of Laponite and alginate, reflected e. g. by charge density and distribution [21], it is possible that the heterogeneous material/ion pattern had an influence on cell behavior. Although, no obvious cell clustering or cell morphology pattern across the scaffolds was observed. Moreover, it is likely the topography of the cross sections which could alter electron detection while EDX mapping and therefore limiting comparison to the different zones, which were seen in the electron microscopy images. Ongoing work is focused on a detailed investigation of the behavior of skeletal stem cell populations embedded in the 3-3-3 bioink.

Comparison of SEM images of day 1 and day 21 revealed that plotted strands retained their shape over the culture period with only modest increase in strand dimensions; Quantification of volumetric swelling supported this observation, as the increase of the width of plotted 3-3-3 strands was approximately $20 \%$ from day 1 to day 21 . It has been previously shown, that Laponite has a positive impact on the swelling properties of alginate gels [36]. However, uniaxial compressive tests revealed a strong change in the mechanical behaviour of the scaffolds. Moreover, comparison of the storage moduli from dynamic mechanical analysis after 1 and 21 days showed a change from a linear curve, indicating a crosslinked hydrogel, to an increasing line with a linear slope, indicating a less crosslinked condition [52]. It has been reported that changes in the degree of crosslinking of an alginate hydrogel network affects both, swelling and resistance against mechanical load $[53,54]$.

The network of the crosslinked 3-3-3 blend appeared to change over time. Alginate gets crosslinked by divalent cations like calcium [55], but was also shown to interact with Laponite [35]. The zwitterionic charge structure of Laponite presents a range of possible modes of interaction with charged polymers. Furthermore the presence of ions such as calcium can cause aggregation of dispersed clay particles and ínitiate gelation through particle-particle interactions. [27]. Therefore, a strong mutual influence of the alginate network formation and the Laponite arrangement can be expected. Migration of calcium ions from the alginate chains to the Laponite particles followed by a rearrangement of the single components might have occurred and resulted in changes of the network structure which caused the drop of stiffness and changes of viscoelastic properties after 21 days. Young's moduli significant decrease after 21 days of culture additionally could be related to excessive protein adsorption by 3-3-3 paste. The interaction of cations, proteins, Laponite discs and alginate chains and its influence on network formation will be object of further investigations. 
Although, degradation of tissue engineering scaffolds is essential for their use in vivo [56], a preservation of the network structure could prove beneficial effects for culture in vitro, e.g. for applying long-term cell culture experiments, which are important for further characterisation or differentiation and maturation of cells in vitro. The latter could be achieved by additional crosslinking steps (e.g. immersion in $\mathrm{CaCl}_{2}$ solutions) carried out regularly at certain time points of culture or by an increased calcium concentration in the medium, which even was shown to be beneficial for skeletal tissue applications [57,58]. Moreover, the presence of alginate inside the bioink enables further control over mechanical properties, due to its strong dependency in the concentration and type of covalent cation, which crosslinks alginate polymer chains [45,59]. In general, the mechanical degradation was observed for solid and porous scaffolds, respectively. As expected, the non-porous, solid scaffolds revealed higher mechanical strength, than porous scaffolds (porosity is central in consideration of mechanical impairment) [56]. Oscillatory frequency sweep measurements showed a distinct lower storage modulus of solid scaffolds, which could be a sign of a less crosslinked hydrogel compared to macroporous scaffolds. The higher surface area of these macroporous scaffolds should be responsible for more effective crosslinking compared to scaffolds with closed macropores.

Cells embedded in the 3-3-3 paste exhibited a higher cell viability (70-75\% active cells) after plotting compared to cells suspended in the 0-3-9 blend [19]. In the absence of Laponite a slight drop in cell viability was observed at earlier time points in 0-3-9 blends whereas cell viability was stable across the time-course in the 3-3-3 blend. This was reflected in the significantly lower viability in 0-39 vs 3-3-3 at day 7. Interestingly, the cells that remained at later time points in 0-3-9 blend displayed a higher proportion of viable cells, albeit at a considerably lower total cell density. In conclusion, Laponite inclusion was beneficial for biological function of the paste. This could be related to the positive influence of Laponite itself, as well as the reduction of the total solid content [9] or the content of methylcellulose. The analysis of living cells was performed by comparison of metabolically active cells and pre-stained cells, defining both, living and dead cells. Counting of the cell number was performed by analysis of microscopic pictures. Thresholding was applied for every single picture, averaged and then applied to all pictures. Then, number of cells was analysed and cell viability was calculated. Cell viability was stable over 21 days, without significant decrease of the cell number over time. Therefore, metabolically inactive, dead cells could likely be a consequence of shear forces while the extrusion process or mixing of the cells with the plotting paste prior to extrusion. Bioprinting through nozzles, forces shear stress inside a gel that can cause cell death $[17,60]$. Over the culture period of 21 days, cells presented a round-shaped morphology indicating limited interaction with the blend components. Favourable characteristics of Laponite, including support of cell proliferation or adhesion [22], were not observed. Alginate is known for its poor cell adhesive properties [61], apparently, in this study, preventing strong cell activity within the cell-laden 3-3-3 paste. Furthermore, the drop of stiffness of the scaffolds could limit cell activity [62]. However, the favourable interactions of Laponite with polarized substances suggest promising options for loading of adhesive and growth factors to the material prior or after plotting, which might promote cell functions [26,63].

In this respect, initial steps were made in loading model proteins BSA and VEGF to Laponitecontaining 3-3-3 paste and Laponite-free paste 0-3-9 before plotting and studying their release from plotted scaffolds. The inclusion of Laponite to the hydrogel changed the protein release kinetics dramatically. Thus, while 0-3-9 showed a high initial burst release of both proteins, 3-3-3 compositions limited burst release of proteins. This may be due to the higher inner porosity of 0-3-9, but likely results from the strong electrostatic binding sites of 3-3-3 caused by Laponite nanodiscs [26], which are not present in 0-3-9. The electrostatic interaction of Laponite with BSA and VEGF 
may also explain smaller differences in the release curves of BSA and VEGF. BSA is negatively charged, while VEGF has a positive total charge. Therefore, different bond strengths of the proteins and Laponite could be a reason for differences between BSA and VEGF release. The obtained results suggested that most of the proteins were still retained inside the 3-3-3 blend after 7 and 21 days, respectively. Similar effects have been found by Ding et al. following FGF2 loading, who demonstrated, that pure Laponite gels released only negligible amount of growth factor after 35 days [63]. It was shown, that different electrostatic interactions within Laponite blends changed growth factor binding and therefore its release [63]. The physical interaction of alginate and Laponite could influence the factor binding capabilities as well; in consequence, a release of growth factors might only be possible due to polymer presence.

\section{Conclusion}

Nanocomposite hydrogels represent an intriguing alternative for 3D bioprinting materials. Particularly, Laponite silicate clay as a versatile nanomaterial can be employed as filler for multiple polymeric platforms. In this paper, a novel nanocomposite from Laponite, alginate and methylcellulose has been synthesized and characterized. The potential of Laponite as a colloidal ligand in alginate and methylcellulose paste has been investigated, allowing decreasing polymeric content and a development towards a potential composite drug deliyery system. Autoclaving of the single components before dissolution led to a paste with appropriate shear thinning properties for extrusion. Post-printing in vitro degradation of the plotted structures could arise from Laponite interaction with alginate and methylcellulose polymeric chains. Further experiments are on-going to confirm the final interaction between 3-3-3 components. After plotting, a high cell viability was obtained, which was maintained over 21 days. Moreover, the bio-functional benefits of Laponite inside the paste were evidenced by the sustained release of the model proteins BSA and VEGF. The current studies demonstrate the exciting potential of a Laponite-alginate-methylcellulose (3-3-3) paste as a robust, scalable, reliable bioink for 3D printing applications.

\section{Acknowledgments}

We thank Prof. M. Schieker (University Hospital of LMU Munich, Germany) for kindly providing the hTERT-MSC. We acknowledge Ms. Ortrud Zieschang for preparation of SEM samples and microscopy facility CFCI for providing equipment and support in cell imaging. The authors are very grateful for help of the group of Prof. J. Alblas (UMC Utrecht, The Netherlands) in the prestaining of cells. The work carried out in this manuscript was supported project grants from the Biotechnology and Biological Sciences Research Council UK (BB/L00609X and BB/LO21072/1) and University of Southampton IfLS, FortisNet and Postgraduate awards to ROCO.

\section{References}

[1] Castilho M, Moseke C, Ewald A, Gbureck U, Groll J, Pires I, Tels smar J and Vorndran E 2014 Direct 3D powder printing of biphasic calcium phosphate scaffolds for substitution of complex bone defects Biofabrication 6015006

[2] Williams J M, Adewunmi A, Schek R M, Flanagan C L, Krebsbach P H, Feinberg S E, Hollister S J and Das S 2005 Bone tissue engineering using polycaprolactone scaffolds fabricated via selective laser sintering Biomaterials 26 4817-27

[3] Butscher A, Bohner M, Doebelin N, Galea L, Loeffel O and Müller R 2013 Moisture based three-dimensional printing of calcium phosphate structures for scaffold engineering Acta Biomater. 9 5369-78 
[4] Schumacher M, Deisinger U, Detsch R and Ziegler G 2010 Indirect rapid prototyping of biphasic calcium phosphate scaffolds as bone substitutes: influence of phase composition, macroporosity and pore geometry on mechanical properties J. Mater. Sci. Mater. Med. 21 3119-27

[5] Lode A, Krujatz F, Brüggemeier S, Quade M, Schütz K, Knaack S, Weber J, Bley T and Gelinsky M 2015 Green bioprinting: Fabrication of photosynthetic algae-laden hydrogel scaffolds for biotechnological and medical applications Eng. Life Sci. 15 177-83

[6] Pfister A, Landers R, Laib A, Hübner U, Schmelzeisen R and Mülhaupt R 2004 Biofunctional rapid prototyping for tissue-engineering applications: 3D bioplotting versus 3D printing J. Polym. Sci. Part Polym. Chem. 42 624-38

[7] Nicodemus G D and Bryant S J 2008 Cell Encapsulation in Biodegradable Hydrogels for Tissue Engineering Applications Tissue Eng. Part B Rev. 14 149-65

[8] Gasperini L, Mano J F and Reis R L 2014 Natural polymers for the microencapsulation of cells J. R. Soc. Interface 1120140817

[9] Malda J, Visser J, Melchels F P, Jüngst T, Hennink W E, Dhert W J A, Groll J and Hutmacher D W 2013 25th Anniversary Article: Engineering Hydrogels for Biofabrication Adv. Mater. 25 $5011-28$

[10] Jungst T, Smolan W, Schacht K, Scheibel T and Groll J 2016,Strategies and Molecular Design Criteria for 3D Printable Hydrogels Chem. Rev. 116 1496-539

[11] Lee J-S, Hong J M, Jung J W, Shim J-H, Oh J-H and Cho D-W 2014 3D printing of composite tissue with complex shape applied to ear regeneration Biofabrication 6024103

[12] Schuurman W, Khristov V, Pot M W, van Weeren P R, Dhert W J A and Malda J 2011 Bioprinting of hybrid tissue constructs with tailorable mechanical properties Biofabrication 3 021001

[13] Akkineni A R, Ahlfeld T, Lode A and Gelinsky M 2016 A versatile method for combining different biopolymers in a core/shell fashion by $3 \mathrm{D}$ plotting to achieve mechanically robust constructs Biofabrication 8045001

[14] Raja N and Yun H 2016 A simultaneous 3D printing process for the fabrication of bioceramic and cell-laden hydrogel core/shell scaffolds with potential application in bone tissue regeneration J. Mater. Chem. B 4 4707-16

[15] Cornock R, Beirne S, Thompson B and Wallace G G 2014 Coaxial additive manufacture of biomaterial composite scaffolds for tissue engineering Biofabrication $\mathbf{6} 025002$

[16] Kesti M, Eberhardt C, Pagliccia G, Kenkel D, Grande D, Boss A and Zenobi-Wong M 2015 Bioprinting Complex Cartilaginous Structures with Clinically Compliant Biomaterials $A d v$. Funct. Mater. $257406-17$

[17] Billiet T, Gevaert E, De Schryver T, Cornelissen M and Dubruel P 2014 The 3D printing of gelatin methacrylamide cell-laden tissue-engineered constructs with high cell viability Biomaterials 35 49-62

[18] Markstedt K, Mantas A, Tournier I, Martínez Ávila H, Hägg D and Gatenholm P 2015 3D Bioprinting Human Chondrocytes with Nanocellulose-Alginate Bioink for Cartilage Tissue Engineering Applications Biomacromolecules 16 1489-96 
[19] Schütz K, Placht A-M, Paul B, Brüggemeier S, Gelinsky M and Lode A 2015 Three-dimensional plotting of a cell-laden alginate/methylcellulose blend: towards biofabrication of tissue engineering constructs with clinically relevant dimensions J. Tissue Eng. Regen. Med.

[20] Carretero M I 2002 Clay minerals and their beneficial effects upon human health. A review Appl. Clay Sci. 21 155-63

[21] Dawson J I and Oreffo R O C 2013 Clay: New Opportunities for Tissue Regeneration and Biomaterial Design Adv. Mater. 25 4069-86

[22] Xavier J R, Thakur T, Desai P, Jaiswal M K, Sears N, Cosgriff-Hernandez E, Kaunas R and Gaharwar A K 2015 Bioactive Nanoengineered Hydrogels for Bone Tissue Engineering: A Growth-Factor-Free Approach ACS Nano 9 3109-18

[23] Schexnailder P and Schmidt G 2009 Nanocomposite polymer hydrogels Colloid Polym. Sci. 287 $1-11$

[24] Thompson D W and Butterworth J T 1992 The nature of laponite and its aqueous dispersions $J$ Colloid Interface Sci $151236-43$

[25] Gibbs D M R, Black C R M, Hulsart-Billstrom G, Shi P, Scarpa E, Oreffo R O C and Dawson J I 2016 Bone induction at physiological doses of BMP through localization by clay nanoparticle gels Biomaterials 99 16-23

[26] Dawson J I, Kanczler J M, Yang X B, Attard G S and Oreffo R O C 2011 Clay gels for the delivery of regenerative microenvironments Adv. Mater. Deerfield Beach Fla 23 3304-8

[27] Zhao L Z, Zhou C H, Wang J, Tong D S, Yu W H and Wang H 2015 Recent advances in clay mineral-containing nanocomposite hydrogels Soft Matter 11 9229-46

[28] Hoppe A, Güldal N S and Boccaccini A R 2011 A review of the biological response to ionic dissolution products from bioactive glasses and glass-ceramics Biomaterials 32 2757-74

[29] Abou B, Bonn D and Meunier J 2003 Nonlinear rheology of Laponite suspensions under an external drive $J$. Rheol. 47 979-988

[30] Pozzo D C and Walker L M 2004 Reversible shear gelation of polymer-clay dispersions Colloids Surf. Physicochem. Eng. Asp. 240 187-198

[31] Luo Y, Lode A and Gelinsky M 2013 Direct Plotting of Three-Dimensional Hollow Fiber Scaffolds Based on Concentrated Alginate Pastes for Tissue Engineering Adv. Healthc. Mater. 2 $777-83$

[32] Sarker B, Singh R, Silva R, Roether J A, Kaschta J, Detsch R, Schubert D W, Cicha I and Boccaccini A R 2014 Evaluation of Fibroblasts Adhesion and Proliferation on Alginate-Gelatin Crosslinked Hydrogel PLOS ONE 9 e107952

[33] Gaetani R, Doevendans P A, Metz C H G, Alblas J, Messina E, Giacomello A and Sluijter J P G 2012 Cardiac tissue engineering using tissue printing technology and human cardiac progenitor cells Biomaterials 33 1782-90

[34] Wu Z, Su X, Xu Y, Kong B, Sun W and Mi S 2016 Bioprinting three-dimensional cell-laden tissue constructs with controllable degradation Sci. Rep. 624474 
[35] Ghadiri M, Chrzanowski W, Lee W H, Fathi A, Dehghani F and Rohanizadeh R 2013 Physicochemical, mechanical and cytotoxicity characterizations of Laponite $\mathbb{R} /$ alginate nanocomposite Appl. Clay Sci. 85 64-73

[36] Li Y, Maciel D, Tomás H, Rodrigues J, Ma H and Shi X 2011 pH sensitive Laponite/alginate hybrid hydrogels: swelling behaviour and release mechanism Soft Matter 7 6231-8

[37] Gonçalves M, Figueira P, Maciel D, Rodrigues J, Shi X, Tomás H and Li Y 2014 Antitumor Efficacy of Doxorubicin-Loaded Laponite/Alginate Hybrid Hydrogels Macromol. Biosci. 14 $110-20$

[38] Hong S, Sycks D, Chan H F, Lin S, Lopez G P, Guilak F, Leong K W and Zhao X 2015 3D Printing of Highly Stretchable and Tough Hydrogels into Complex, Cellularized Structures $A d v$. Mater. 27 4035-40

[39] Jin Y, Liu C, Chai W, Compaan A and Huang Y 2017 Self-Supporting Nanoclay as Internal Scaffold Material for Direct Printing of Soft Hydrogel Composite Structures in Air ACS Appl. Mater. Interfaces 9 17456-65

[40] Landers R, Pfister A, Hübner U, John H, Schmelzeisen R and Mülhaupt R 2002 Fabrication of soft tissue engineering scaffolds by means of rapid prototyping techniques J. Mater. Sci. 37 $3107-16$

[41] Böcker W, Yin Z, Drosse I, Haasters F, Róssmann O, Wierer M, Popov C, Locher M, Mutschler W, Docheva D and Schieker M 2008 Introducing a single-cell-derived human mesenchymal stem cell line expressing hTERT after lentiviral gene transfer J. Cell. Mol. Med. 12 1347-59

[42] Knaack S, Lode A, Hoyer B, Rösen-Wolff A, Gabrielyan A, Roeder I and Gelinsky M 2014 Heparin modification of a biomimetic bone matrix for controlled release of VEGF J. Biomed. Mater. Res. A 102 3500-11

[43] Ferris C J, Gilmore K G, Wallace G G and In het Panhuis M 2013 Biofabrication: an overview of the approaches used for printing of living cells Appl. Microbiol. Biotechnol. 97 4243-58

[44] Khalil S and Sun W 2009 Bioprinting Endothelial Cells With Alginate for 3D Tissue Constructs J. Biomech. Eng. 131 111002-111002-8

[45] Tabriz A G, Hermida MA, Leslie N R and Shu W 2015 Three-dimensional bioprinting of complex cell laden alginate hydrogel structures Biofabrication 7045012

[46] Bandeira L C, Calefi P S, Ciuffi K J, de Faria E H, Nassar E J, Vicente M A and Trujillano R 2012 Preparation of composites of laponite with alginate and alginic acid polysaccharides Polym. Int. $611170-6$

[47] Knarr M and Bayer R 2014 The shear dependence of the methylcellulose gelation phenomena in aqueous solution and in ceramic paste Carbohydr. Polym. 111 80-8

[48] Bernhardt A, Wehrl M, Paul B, Hochmuth T, Schumacher M, Schütz K and Gelinsky M 2015 Improved Sterilization of Sensitive Biomaterials with Supercritical Carbon Dioxide at Low Temperature PLOS ONE 10 e0129205

[49] Ruzicka B, Zulian L and Ruocco G 2004 Routes to gelation in a clay suspension Phys. Rev. Lett. 93258301

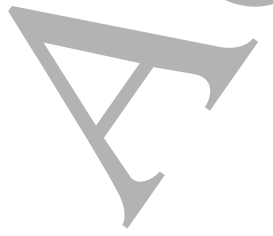


[50] Nasatto P L, Pignon F, Silveira J L M, Duarte M E R, Noseda M D and Rinaudo M 2015 Methylcellulose, a Cellulose Derivative with Original Physical Properties and Extended Applications Polymers 7 777-803

[51] Sarkar N and Walker L C 1995 Hydration - dehydration properties of methylcellulose and hydroxypropylmethylcellulose Carbohydr. Polym. 27 177-85

[52] Choi B, Loh X J, Tan A, Loh C K, Ye E, Joo M K and Jeong B 2015 Introduction to In Situ Forming Hydrogels for Biomedical Applications In-Situ Gelling Polymers Series in BioEngineering ed X J Loh (Springer Singapore) pp 5-35

[53] Naficy S, Kawakami S, Sadegholvaad S, Wakisaka M and Spinks G M 2013 Mechanical properties of interpenetrating polymer network hydrogels based on hybrid ionically and covalently crosslinked networks J. Appl. Polym. Sci. 130 2504-13

[54] Kuo C K and Ma P X 2001 Ionically crosslinked alginate hydrogels as scaffolds for tissue engineering: Part 1. Structure, gelation rate and mechanical properties Biomaterials 22 511-21

[55] Lee K Y and Mooney D J 2012 Alginate: properties and biomedical applications Prog. Polym. Sci. 37 106-26

[56] O’Brien F J 2011 Biomaterials \& scaffolds for tissue engineering Mater. Today 14 88-95

[57] Nakamura S, Matsumoto T, Sasaki J-I, Egúsa H, Lee K Y, Nakano T, Sohmura T and Nakahira A 2010 Effect of Calcium Ion Concentrations on Osteogenic Differentiation and Hematopoietic Stem Cell Niche-Related Protein Expression in Osteoblasts Tissue Eng. Part A 16 2467-73

[58] Danoux C B S S, Bassett D C, Othman Z, Rodrigues A I, Reis R L, Barralet J E, van Blitterswijk $\mathrm{C} A$ and Habibovic P 2015 Elucidating the individual effects of calcium and phosphate ions on hMSCs by using composite materials Acta Biomater. 17 1-15

[59] Mørch Y A, Donati I, Strand B L and Skjåk-Braek G 2006 Effect of Ca2+, Ba2+, and Sr2+ on alginate microbeads Biomacromolecules 7 1471-80

[60] Blaeser A, Duarte Campos D F, Puster U, Richtering W, Stevens M M and Fischer H 2016 Controlling Shear Stress in 3D Bioprinting is a Key Factor to Balance Printing Resolution and Stem Cell Integrity Adv. Healthc. Mater. 5 326-33

[61] Sarker B, Rompf J, Silva R, Lang N, Detsch R, Kaschta J, Fabry B and Boccaccini A R 2015 Alginate-based hydrogels with improved adhesive properties for cell encapsulation Int. J. Biol. Macromol. 78 72-8

[62] Mason B N, Califano J P and Reinhart-King C A 2012 Matrix Stiffness: A Regulator of Cellular Behavior and Tissue Formation Engineering Biomaterials for Regenerative Medicine ed S K Bhatia (Springer New York) pp 19-37

[63] Ding X, Gao J, Wang Z, Awada H and Wang Y 2016 A shear-thinning hydrogel that extends in vivo bioactivity of FGF2 Biomaterials $11180-9$ 